\title{
PROTEÇÃO LEGAL À AMAMENTAÇÃO, NA PERSPECTIVA DA RESPONSABILIDADE DA FAMÍLIA E DO ESTADO NO BRASIL
}

\author{
Right to breastfeeding, right to health and family: \\ the legal protection network in Brazil \\ Isabel Maria Sampaio Oliveira Lima* \\ Thiago Marques Leão** \\ Miriã Alves Ramos Alcântara***
}

\begin{abstract}
RESUMO
O objetivo deste estudo é analisar a proteção legal à amamentação, na perspectiva da responsabilidade da família e do Estado, no Brasil. Adotou-se uma abordagem qualitativa com identificação e análise das normas de proteção ao direito à amamentação, com destaque para a inovação constitucional do direito fundamental à amamentação. Caracterizou-se, assim, a fundamentalidade do direito à amamentação como Direito Humano autônomo e, também, como desdobramento do direito à saúde. Identificou-se o arcabouço legal de proteção e promoção à amamentação, notadamente, os direitos da mãe trabalhadora, o direito à alimentação e à saúde da criança e a regulação do comércio de fórmulas que fomentam a interrupção precoce da amamentação. O estudo identificou que o Brasil possui uma proteção legal abrangente à amamentação e uma política consistente nesse sentido. Deve-se dar continuidade a essas ações, buscando educar a família, a sociedade, profissionais de saúde e gestores sobre a importância da amamentação e seu relevo na promoção da saúde materno-infantil.
\end{abstract}

Palavras-chave: Amamentação; Direitos Humanos; Família; Saúde.

* Doutora em Saúde Pública, Instituto de Saúde Coletiva, Universidade Federal da Bahia. Professora visitante, Universidade Federal do Sul da Bahia; Professora colaboradora, Instituto de Saúde Coletiva, Universidade Federal da Bahia; Juíza de Direito. Salvador/BA - Brasil. E-mail: isabelmsol@gmail.com

** Mestre e Doutorando, Faculdade de Saúde Pública, Universidade de São Paulo. Pesquisador do Grupo de Pesquisa Humanos, Direito à Saúde e Família, Universidade Federal da Bahia. São Paulo/SP - Brasil. E-mail: thmleao@gmail.com

***Doutora em Saúde Pública, Instituto de Saúde Coletiva, Universidade Federal da Bahia. Professora Titular e coordenadora do Programa de Pós-Gradução em Família na Sociedade Contemporânea, Universidade Católica de Salvador. Grupo do Diretório de Pesquisa (CNPq) Família em Mudança. Psicóloga. Salvador/BA - Brasil. E-mail: miria.alcantara@gmail.com

Artigo recebido em: 27/02/2011. Revisado em: 16/06/2011. Nova revisão em: 30/11/2011 Aprovado em 22/12/2011. 


\begin{abstract}
The purpose of this study was to analyze the legal protection of breastfeeding from the perspective of the family and the State's responsibility, in Brazil. The study was conducted with a qualitative approach to identify and analyze the norms that protects the right to breastfeed, especially the constitutional innovation of the fundamental right to breastfeeding. It was characterized the fundamentality of this right as an autonomous human right and also as a dimension of the right to health. It was identified the legal framework that protects and promotes breastfeeding, especially the rights of working mothers, the children's right to nutrition and health and the regulation of formulas that promote premature stop of breastfeeding. The study concludes that Brazil has a comprehensive legal protection for breastfeeding and a consistent policy in this area. It should continue these actions, seeking to educate the family, society, health professionals and managers about the benefits of breastfeeding and its importance in promoting maternal and child health.
\end{abstract}

Keywords: Breastfeeding; Family; Health; Human Rights.

\title{
Introdução
}

O objetivo deste estudo é analisar a proteção legal à amamentação, na perspectiva da responsabilidade da família e do Estado, no Brasil. Adotou-se uma abordagem metodológica qualitativa que, perante a complexidade do tema estudado, permite uma análise em profundidade para o reconhecimento de conflitos, suas causas e estratégias de enfrentamento.(1) $\mathrm{O}$ artigo divide-se em quatro seções em que são indicadas e analisadas as normas (constitucionais, legais e infralegais) de proteção, direta e indireta, à amamentação no Brasil.

\section{Família, Estado e amamentação}

Objeto de interesse de diferentes áreas do conhecimento e prática que mobiliza atores e grupos sociais diversos, a amamentação sempre recebeu atenção especial, por ser um dos processos humanos que integram dimensões de natureza biológica, psíquica e social. A amamentação é tema transversal à literatura clássica das ciências humanas desde os estudos da Etologia e do modelo proposto por John Bowlby, ${ }^{(2)}$ ambos convergentes com as observações de Renè Spitz ${ }^{(3)}$ a respeito dos efeitos da privação do contato e do cuidado parental no primeiro ano de vida da criança. A linha de pensamento sobre a qual se ancora a análise

\footnotetext{
1 VICTORIA, Ceres Gomes; KNAUTH, Daniela Riva; HASSEN, Maria de Nazareth Agra. Pesquisa qualitativa em saúde: uma introdução ao tema. Porto Alegre: Tomo Editorial, 2000.

2 BOWLBY, John. Apego e perda: apego, a natureza do vínculo. 2. ed. São Paulo: Martins Fontes, 1990. v. 1.

${ }^{3}$ SPITZ, Rene. O primeiro ano de vida. 6. ed. São Paulo: Martins Fontes, 1991.
} 
do desenvolvimento humano como processo resultante de elementos da biologia e da cultura é constituída por vertentes teóricas que, apesar de divergirem a respeito da natureza e do processo do desenvolvimento, convergem na compreensão da interação de diversas forças não arbitrárias em jogo.

A partir dessa perspectiva, na literatura contemporânea trata-se da amamentação a partir da convergência das ciências da saúde e das ciências humanas em torno dos efeitos benéficos e duráveis à saúde da mulher e ao ciclo evolutivo do bebê. Seu tratamento através de diferentes objetos e métodos tem conduzido a resultados que corroboram os achados das ciências do desenvolvimento humano, além de oferecerem subsídios a políticas de humanização da gravidez, do parto e do puerpério em perspectiva multidisciplinar.

A amamentação constitui uma das dimensões fundamentais do cuidado à saúde da mulher e da proteção da criança que demandam a integração de duas instâncias: família e Estado. As famílias possuem estruturas organizacionais diversificadas que necessitam ser consideradas de forma integral de modo a assegurar-lhes meios de inclusão social no interior das relações sociais. Embora esteja a amamentação na órbita do cuidado nomeadamente familiar, outras dimensões - comunitária e estatal - agregam suas forças, seja de ordem da solidariedade, seja de ordem legislativa e das políticas públicas.

A amamentação passou por profundas transformações. Há séculos, o desmame e os cuidados ao bebê por figuras substitutivas, como as amas de leite, acompanham a educação da infância e a maternidade, imprimindo nas transformações do corpo feminino novos ritmos e contornos, definidos pela sociabilidade.

Por razões diversas torna-se a amamentação um fenômeno provável e não determinado pela evolução humana, em contraste com o que ocorre com os primatas. ${ }^{(4)}$ A influência de variáveis sociais, econômicas e educacionais sobre o tempo de amamentação e seu impacto sobre os índices de desnutrição e mortalidade infantil é reportado nos documentos internacionais. ${ }^{(5)}$ Em todo o mundo morrem, a cada ano, mais de 10 milhões de crianças menores de cinco anos por causas evitáveis. No Brasil, esse índice encontra-se em torno de 20,7 óbitos por mil nascidos vivos por ano. Dentre as diversas intervenções de caráter preventivo e terapêutico, com elevada eficácia e custo reduzido, está o aleitamento materno.

$\mathrm{O}$ ato de amamentar, longe de ser um processo simples, equivocadamente entendido como consequência "natural" da maternidade, em muitos casos representa mais um desafio a requerer adaptações diversas, desde a autoimagem, aos odores, líquidos e ritmos que circunscrevem a mulher ao foco de um bebê pleno de demandas. A adoção de outros padrões de alimentação

\footnotetext{
${ }^{4}$ BUSSAB, V. S. R. A família humana vista da perspectiva etológica: natureza ou cultura? Interação, Curitiba, v. 4, p. 9-22, 2000.

5 UNITED NATIONS DEVELOPMENT PROGRAMME. Capacity Development - Empowering People and Institutions. Annual Report, PNUD, 2008.
} 
para o bebê não se deve, muitas vezes, a uma opção, mas às necessárias adaptações do seio e da disponibilidade maternas ao ritmo impresso pela amamentação exclusiva. Esse conjunto de desafios ocultos no discurso da amamentação, seja processo natural, seja como um bem para o bebê e para o vínculo mãe e filho, foi enfrentado a partir do apoio da secular figura da ama de leite até o emblemático avanço da ciência representado pelos leites modificados. Constata-se que a alimentação do lactente está envolta em questões que não se referem de modo exclusivo à saúde, denotando, em muitas situações, interesses relacionados à modulação de comportamento social e à oportunidade de obter lucro. ${ }^{(6)}$ Esse quadro requer a atenção ao direito da mulher na sua integridade e dignidade, a ser respeitado e compreendido como via de democracia e de solidariedade social.

A amamentação, processo influenciado positiva e negativamente por fatores relacionados à mãe - como as características de sua personalidade e sua atitude frente à situação de amamentar -, à criança e à gestação - como as condições de parto, o período pós-gestacional e o temperamento da criança -, sofre, sobretudo, a influência de fatores circunstanciais, tais como o trabalho materno, a geração e as condições do cotidiano. Todos os aspectos intervenientes da amamentação são sintetizados nas justificativas dadas ao desmame precoce ou à continuidade do aleitamento. Trata-se de um sistema bidirecional de valores e crenças que afeta e influencia as práticas de cuidado, transformando e modificando-se na interação com o ambiente físico e social. É nessa dinâmica complexa que se situam a amamentação, o cuidado e os processos de desenvolvimento da família.

As mais recentes revisões sobre o tema revelam o imbricado jogo em torno das concepções de amamentação e construtos derivados da vivência da feminilidade e do condicionamento das condições de classe. No entanto, há certo consenso de que as cognições parentais atuam como mediadores, influenciando as práticas de cuidado e os comportamentos parentais. Esses apresentam efeitos diversos sobre o comportamento das crianças e o desenvolvimento da família. ${ }^{(7)}$

Ações de caráter educacional, implementadas pelo Estado no setor saúde, desde a formação médica até o planejamento do pré-natal para o aconselhamento em amamentação, visam oferecer suporte e monitoramento, e promovem mudanças na cognição e no comportamento parental por meio da informação. ${ }^{(8)}$ Embora

\footnotetext{
${ }^{6}$ ALMEIDA, Jag; NOVAK, FR. Amamentação: um híbrido natureza-cultura. Jornal de Pediatria, v. 80, n. 5, 2004.

7 RIBAS JR, R; MOURA, M.L.S; BORNSTEIN, M. H. Socioeconomic status in Brazilian psychological research: II. Socioeconomic status and parenting knowledge. Estudos de Psicologia, v. 8, 2003. Disponível em: <http://www.scielo.br/scielo.php?script=sci_arttext\&pid=S1413294X2003000300005>. Acesso em: 11 jan. 2014.

${ }^{8}$ GALVÃO, D. M. P. G. Amamentação bem sucedida: alguns fatores determinantes. Loures: Lusociência Ed. Técnicas e Cientificas, 2006.
} 
implique em uma dimensão individual de cuidado envolvendo a mãe-nutriz e o seu bebê, a amamentação enseja a coparticipação da família e do Estado na perspectiva do direito da mulher e da criança cuja atuação conjunta e subsidiária fortalece o tecido social, a exemplo do que acontece em diversos países europeus. Muito embora perdurem disparidades regionais e de classe, o Brasil tem apresentado mudanças quanto à abrangência do acesso aos direitos fundamentais, em especial no campo da saúde.

A amamentação é uma das dimensões de cuidado contínuo, cuja natureza intimamente familiar não pode ser suprida pela atuação do Estado. Embora historicamente a prática do aleitamento tenha sido atribuída a mulheres fora do círculo familiar, a amamentação é reconhecida como uma relação exclusiva entre a mãe e sua criança. Em que pese o necessário papel do poder público, na garantia e proteção à amamentação, a família desempenha papel central e indispensável na dinâmica de proteção à criança.

Além de marcada por aspectos de natureza fisiológica, a amamentação é condicionada por dimensões socioculturais, tratando-se, portanto, de um ato impregnado de determinantes que resultam das condições concretas de vida. A família integra tais condições sendo mais bem retratada através da metáfora da rede do que por meio da ideia de estrutura, extremamente rígida e padronizada. A família, independentemente da sua configuração, como rede tem o potencial de fornecer apoio aos atores que a integram. A rede social que apoia a amamentação atua através do incentivo, da proximidade entre os atores e da comunicação referencial de valores e conhecimentos. A família, portanto, integra a rede de apoio social materno-infantil, como espaço nuclear de promoção da amamentação e cuidado. Ela é agente de incentivo, apoio e referencial de valores e conhecimentos. É no espaço familiar que a mãe troca experiências sobre alimentação do bebê, saberes e práticas, que variam de acordo com a história de vida dessas famílias. ${ }^{(9)}$ Especialmente junto às avós e outras mães, a lactante identifica figuras femininas, com a prerrogativa de já terem vivido a maternidade e a amamentação, reforçando a importância do aleitamento materno e do cuidado. ${ }^{(10)}$

A família constitui o primeiro referencial para a mulher no processo de amamentação. É no convívio entre as pessoas que nutrem relação de afeto e de

\footnotetext{
${ }^{9}$ MARQUES, Emanuele Souza et al. A influência da rede social da nutriz no aleitamento materno: o papel estratégico dos familiares e dos profissionais de saúde. Ciência e Saúde Coletiva, Rio de Janeiro, v. 15, suppl. 1, p. 1391-1400, 2011. SciELO Brasil. Disponível em: <http://www.scielo.br/ scielo.php?script=sci_arttext\&pid=S1413-81232010000700049\&lng=pt\&nrm=iso>. Acesso em: 19 jan. 2014. doi: 10.1590/S1413-81232010000700049.

${ }^{10}$ TEIXEIRA, Marizete Argolo; NITSCHKE, Rosane Gonçalves. Modelo de cuidar em enfermagem junto às mulheres-avós e sua família no cotidiano do processo de amamentação. Texto Contexto - enferm. Florianópolis, v. 17, n. 1, p. 183-191, mar. 2008. SciELO Brasil. Disponível em: <http:// www.scielo.br/scielo.php?script=sci_arttext\&pid=S0104-07072008000100021\&lng=pt\&nrm=iso $>$. Acessos em: 19 jan. 2014. doi: 10.1590/S0104-07072008000100021; MARQUES, Emanuele Souza et al. op. cit.
} 
cuidado que os valores, as crenças e as práticas são transmitidas, ${ }^{(11)}$ razão pela qual se deve reconhecer seu valor na garantia da saúde da criança e na retomada da amamentação como regra no cuidado e na intimidade do binômio materno-infantil. Cabe ao Estado promover a educação em saúde, para fortalecer a atuação das famílias, a troca de experiências e saberes acumulados durante a vida. Além de atuar na efetivação do direito à amamentação, em condições adequadas de forma integral e universal, é responsabilidade do Estado reconhecer o papel da família e, junto com ela, atuar na consolidação da amamentação como estratégia de atenção à saúde.

O apoio à lactante, por parte da família, sociedade, profissionais de saúde e do Estado, é um eixo essencial à efetividade do direito à amamentação. Marques et $a^{\left({ }^{(12)}\right.}$ apontam a família como um dos principais fatores na promoção da amamentação pelo estímulo e pela troca de conhecimentos e valores. Essa integração intergeracional na instância familiar pode, no entanto, vir a ter um potencial impacto negativo, quando desestimula o aleitamento materno. Barbosa et $\mathrm{al}^{\left({ }^{(13)}\right.}$ demonstram que as características relacionadas à família estão entre as principais causas de desmame precoce. Esses dados reforçam a percepção da necessidade de promover a educação em saúde das famílias e dos profissionais de saúde que as orientam.

\section{Direito sanitário e amamentação}

A Constituição Federal de 1988 (CF/88) é o marco de retomada democrática e do projeto de Estado social brasileiro. Trata-se, em essência, de uma constituição axiologicamente refratária ao individualismo, que prioriza o interesse coletivo e a cidadania. ${ }^{(14)}$ Para concretizar esses valores, elenca uma série de direitos fundamentais individuais e sociais, com vistas à redução das desigualdades historicamente estabelecidas, no cenário brasileiro. Esses direitos fundam-se na ética emancipatória dos Direitos Humanos, que demanda transformações sociais, com a promoção da igualdade, dignidade e não violência. ${ }^{(15)}$

\footnotetext{
${ }^{11}$ NAKANO, Ana Márcia Spanó et al. Women's social space and the reference for breastfeeding practice. Revista Latino-Americana de Enfermagem, Ribeirão Preto, v. 15, n. 2, p. 230238, abr. 2007. SciELO Brasil. Disponível em: <http://www.scielo.br/scielo.php?script=sci_ arttext\&pid=S0104-11692007000200007\&lng=pt\&nrm=iso>. Acesso em: 19 jan. 2014. doi: 10.1590/ S0104-11692007000200007.

${ }^{12}$ MARQUES, Emanuele Souza et al. op. cit.

${ }^{13}$ BARBOSA, Marina Borelli; PALMA, Domingos. Fatores de risco associados ao desmame precoce e ao período de desmame em lactentes matriculados em creches. Revista Paulista de Pediatria, São Paulo, v. 27, n. 3, p. 272-281, set. 2009. SciELO Brasil. Disponível em: <http://www.scielo.br/ scielo.php?script=sci_arttext\&pid=S0103-05822009000300007\&lng=pt\&nrm=iso>. Acesso em: 19 jan. 2014. doi: 10.1590/S0103-05822009000300007.

${ }^{14}$ BONAVIDES, Paulo. Curso de direito constitucional. 21. ed. São Paulo: Malheiros Ed., 2007.

${ }^{15}$ PIOVESAN, Flávia. Temas de direitos humanos. 3. ed. São Paulo: Saraiva, 2009.
} 
Nesse sentido, um dos principais avanços da CF/88 é o reconhecimento do direito fundamental à saúde (artigos $6^{\circ}$ e 196), ${ }^{(16)}$ que até então contava com uma proteção jurídica indireta e limitada, em termos constitucionais. ${ }^{(17)}$ Apesar de o ordenamento jurídico brasileiro contar, até o momento, com arcabouço de normas sobre vigilância sanitária, controle de drogas e medicamentos, ${ }^{(18)}$ este não tinha o caráter universal, integral e prestacional, com vistas à promoção da saúde, inaugurado na CF/88.

Representa a CF/88, portanto, um marco jurídico de proteção à saúde, fincado durante o processo de restabelecimento do Estado Democrático de Direito no Brasil, após o período de ditadura militar. O contexto de redemocratização abriu espaço para um ambiente de proteção e emergência dos direitos humanos e potencializou, assim, a garantia do direito à saúde. O restabelecimento do Estado de Direito no Brasil, orientado pelo respeito aos princípios democráticos, "representa a garantia primeira para que o direito à saúde seja uma realidade".(19)

A CF/88 e o Sistema Único de Saúde (SUS), que foi inaugurado em 1988 mediante lutas de mobilização por esse direito social, emergem desse contexto histórico-político de redemocratização brasileira. Nesse cenário identificam-se novos sujeitos na esfera política e novas expectativas de ampliação da rede de seguridade social. ${ }^{(20)}$ Como sustenta Fleury, (21) "a luta pela universalização da saúde aparece como uma parte intrínseca da luta pela democracia, assim como a institucionalização da democracia aparece como condição para garantia da saúde como direito de cidadania". Nesse imbricamento, de caráter sociopolítico, somam-se planos de integração da cidadania: primeiramente mediada pela garantia do direito humano, de caráter social, a saúde fortalece a pessoa

\footnotetext{
${ }^{16}$ Art. 60: "São direitos sociais a educação, a saúde, a alimentação, o trabalho, a moradia, o lazer, a segurança, a previdência social, a proteção à maternidade e à infância, a assistência aos desamparados, na forma desta Constituição". Art. 196: "A saúde é direito de todos e dever do Estado, garantido mediante políticas sociais e econômicas que visem à redução do risco de doença e de outros agravos e ao acesso universal e igualitário às ações e serviços para sua promoção, proteção e recuperação". BRASIL. Constituição da República Federativa do Brasil de 1988. Disponível em: <http://www.planalto. gov.br/ccivil_03/constituicao/ConstituicaoCompilado.htm>. Acesso em: 13 jan. 2014.

${ }^{17}$ SARLET, Ingo Wolfgang; FIGUEIREDO, Mariana Filchtiner. Algumas considerações sobre o direito fundamental à proteção e promoção do direito à saúde aos 20 anos da Constituição Federal de 1988 In: KEINERT, Tânia Margarete Mezzomo; PAULA, Silvia Helena Bastos de; BONFIM, José Ruben de Alcântara (Orgs.). As ações judiciais no SUS e a promoção do direito à saúde. São Paulo: Instituto de Saúde, 2009. p. 25-63.

${ }^{18}$ AITH, Fernando. Curso de direito sanitário: a proteção do direito à saúde no Brasil. São Paulo: Quatier Latin, 2007.

${ }^{19}$ Id. Ibid.

${ }^{20}$ SOLON, Ari Marcelo. Ética, cidadania e direito à saúde In: KEINERT, Tânia Margarete Mezzomo; PAULA, Silvia Helena Bastos de; BONFIM, José Ruben de Alcântara (Orgs.). As ações judiciais no SUS e a promoção do direito à saúde. São Paulo: Instituto de Saúde, 2009. p. 21-24.

${ }^{21}$ FLEURY, Sônia. A reforma sanitária: processo histórico. In: BANCO INTERNACIONAL DE DESENVOLVIMENTO (BID). A construção da reforma sanitária no Brasil e os desafios para os gestores. 2. ed. INDES, 2009 p. 11.
} 
individualmente e na perspectiva do coletivo; de forma simultânea, a democracia, por sua vez, fortalece o tecido social.

A amamentação, de acordo com a Organização Mundial da Saúde (OMS), "é a melhor maneira de proporcionar o alimento ideal para o crescimento saudável e o desenvolvimento dos recém-nascidos, além de ser parte integral do processo reprodutivo, com importantes implicações para a saúde materna". (22) Especialmente para famílias pobres, é um meio de prevenir a contaminação durante o preparo da mamadeira e a desnutrição, devido a fórmulas excessivamente diluídas, ${ }^{(23)}$ além de conferir todas as vantagens de imunização e nutrição do lactente.

O Ministério da Saúde (MS) ressalta o efeito protetor do leite materno contra a mortalidade infantil, advertindo que, quão mais cedo se inicie a amamentação e maior for seu período, maior a proteção à saúde da criança. ${ }^{(24)}$ O MS aponta uma série de estudos que evidenciam os benefícios à saúde da criança trazidos pela amamentação, em oposição aos riscos de um desmame precoce, com destaque para a menor prevalência de alergias, a prevenção a doenças crônicas não transmissíveis e um melhor desenvolvimento neurológico.

Para além dos benefícios à saúde da criança, têm-se discutido os efeitos positivos da amamentação, tanto na melhor evolução do puerpério, ao acionar o sistema hormonal a atuar no fortalecimento do aparelho reprodutor feminino na proteção contra o câncer de mama e de ovário na mulher, quanto na promoção do vínculo afetivo entre mãe e filho, por força do aleitamento materno. ${ }^{25)}$ A amamentação é a mais humana, sensível, eficaz e economicamente viável intervenção para redução da morbimortalidade infantil, promovendo a saúde integral tanto da mãe como da criança e prevenindo distúrbios nutricionais de grande impacto para a coletividade e para saúde pública. ${ }^{(26)}$

${ }^{22}$ ORGANIZAÇÃO MUNDIAL DA SAÚDE. Organização Pan-Americana da Saúde. Amamentação. 2003. Disponível em: <http://www.opas.org.br/sistema/fotos/amamentar.pdł>. Acesso em: 13 jan. 2014.

${ }^{23}$ MONTEIRO, Juliana Cristina dos Santos; GOMES, Flávia Azevedo; NAKANO, Ana Márcia Spanó. Amamentação e o seio feminino: uma análise sob a ótica da sexualidade e dos direitos reprodutivos. Texto Contexto - enferm., Florianópolis, v. 15, n. 1, p. 146-150, mar. 2006. SciELO Brasil. Disponível em: <http://www.scielo.br/scielo.php?script=sci_arttext\&pid=S0104-07072006000100018\&lng=pt\& $\mathrm{nrm}=\mathrm{iso}>$. Acesso em: 19 jan. 2014. doi: 10.1590/S0104-07072006000100018.

${ }^{24}$ BRASIL. Ministério da Saúde. Secretaria de Política de Saúde. Organização Pan Americana da Saúde. Guia alimentar para crianças menores de dois anos. Secretaria de Políticas de Saúde, Organização Pan Americana da Saúde. Brasília: Ministério da Saúde, 2002.

${ }^{25}$ ARAÚJO, Maria de Fátima Moura de et al. Custo e economia da prática do aleitamento materno para a família. Revista Brasileira de Saúde Materno Infantil, Recife, v. 4, n. 2, p. 135-141, jun. 2004. SciELO Brasil. Disponível em: <http://www.scielo.br/scielo.php?script=sci_arttext\&pid=S151938292004000200003\&lng=pt\&nrm=iso>. Acesso em: 19 jan. 2014. doi: 10.1590/S151938292004000200003.

${ }^{26}$ BRASIL. Ministério da Saúde. Secretaria de Atenção à Saúde. Departamento de Atenção Básica. Saúde da criança: nutrição infantil. Aleitamento materno e alimentação complementar. Ministério da Saúde, Secretaria de Atenção à Saúde, Departamento de Atenção Básica. - Brasília: Ed. do Ministério da Saúde, 2009. 112 p. (Série A. Normas e Manuais Técnicos) (Cadernos de Atenção Básica, n. 23). 


\section{III. $\mathrm{O}$ direito humano fundamental à amamentação(27)}

A fundamentalidade do direito à amamentação é um tema especialmente complexo, com desdobramentos na relação entre indivíduos e na relação destes indivíduos com a sociedade e o Estado. Na esfera privada, a amamentação envolve necessariamente dois sujeitos de direitos: a nutriz e a criança. Na esfera pública, a amamentação estabelece uma relação jurídica bilateral atributiva entre mãe e criança, de um lado, e o Estado e a sociedade, de outro.

A bilateralidade atributiva é a relação estabelecida entre dois ou mais sujeitos, atribuindo-se a determinado(s) sujeito(s) a titularidade do direito e a outro(s) a exigibilidade de certa conduta. ${ }^{(28)}$ Assim, à criança é garantido o direito à alimentação saudável e em condições de higiene e segurança adequadas, como dimensão de atenção e cuidado. À lactante, o direito a amamentar implica na garantia de condições para fazê-lo, se assim escolher, sem prejuízo ou relativização de quaisquer direitos e sem sofrer quaisquer formas de violência ou discriminação, por parte da sociedade ou do Estado.

Nesse sentido, fica obrigada a sociedade de se abster de quaisquer atos de discriminação ou violência (em sentido amplo) que possa tolher em alguma medida a opção da lactante em amamentar, seja no local de trabalho, em sua residência, seja, se assim entender necessário, em espaços públicos. Quanto ao Estado, reconhecida a fundamentalidade do direito à amamentação e sua natureza social, fica obrigado a tomar as medidas necessárias a sua efetivação, em condições adequadas, abstendo-se de qualquer ato, executivo ou legislativo, que possa ir de encontro a este direito.

A amamentação é um fenômeno complexo, havendo variáveis diversas de natureza fisiológica, psicológica, social e volitiva, dentre outras. O direito de amamentar, nesse contexto, não corresponde a uma obrigação da lactante, mas ao dever do Estado de, no seu espectro de ação, garantir as condições para que a mulher amamente se optar por e puder fazê-lo, e ao da sociedade respeitar o direito da mulher e da criança.

A fundamentalidade, tanto formal quanto material, do direito à amamentação, especialmente no Brasil, é transparente porque, formalmente, a CF/88 consagra, sob o Título II - Dos Direitos e Garantias Fundamentais -, o rol de direitos humanos positivados pelo ordenamento brasileiro. Entre eles, o texto constitucional elenca o direito à saúde, alimentação e proteção à maternidade e à infância (artigo $6^{\circ}$, caput).

\footnotetext{
${ }^{27}$ Neste estudo, utiliza-se as terminologias direitos humanos e direitos fundamentais como sinônimos. Alinhamo-nos ao entendimento de que há equivalência entre as duas expressões, isto é, a "expressão direitos humanos é uma forma abreviada de mencionar os direitos fundamentais da pessoa humana". (DALLARI, Dalmo de Abreu. Direitos humanos e cidadania. 10. ed. São Paulo: Moderna, 2004).

${ }^{28}$ REALE, Miguel. Filosofia do direito. 19. ed. São Paulo: Saraiva, 1999.
} 
A CF/88 é a primeira a consagrar expressamente o direito à amamentação para a criança e para a mulher presidiária, no artigo $5^{\circ}$, inciso $L,{ }^{(29)}$ traduzido no direito de permanecer com seus filhos durante o período de amamentação. Ainda que dirigido às mulheres que se encontram privadas de liberdade, a previsão inédita no texto constitucional é significativa.

Seguindo nessa direção, no parágrafo $3^{\circ}$ do mesmo artigo, os legisladores constitucionais atribuíram, aos tratados e convenções internacionais de direitos humanos, hierarquia de norma constitucional, de aplicabilidade imediata (artigo $5^{\circ}$, parágrafo $1^{\circ}$ ). O ordenamento constitucional brasileiro, portanto, opta por um sistema misto de proteção aos direitos fundamentais, pela incorporação de direitos humanos enunciados em tratados e convenções internacionais, àqueles elencados internamente, no texto constitucional. ${ }^{(30)}$

Internacionalmente, o direito à amamentação é enunciado em diversos diplomas de direitos humanos, como a Convenção de Proteção à Maternidade $n^{\circ} 103$ de 1952 (CPM/103), ${ }^{(31)}$ da Organização Internacional do Trabalho; a Convenção sobre a Eliminação de todas as formas de Discriminação contra a Mulher (CETFDM), de 1979;(32) e a Convenção sobre os Direitos da Criança (CDC), ${ }^{(33)}$ da Organização das Nações Unidas (ONU). Nesses diplomas internacionais, a amamentação - ou aleitamento materno, denominação dada pela OMS - é protegida em diversos dispositivos.

O artigo $12^{\circ}$ da CETFDM impõe aos Estados-Partes a assistência apropriada à mulher antes, durante e após o parto, com nutrição condizente durante a gravidez e o aleitamento. No mesmo sentido, a CDC reconhece o direito à saúde da criança, para redução da mortalidade infantil e da desnutrição, direito à assistência pré-natal e pós-natal, assegurando "que todos os setores da sociedade, e em especial os pais e as crianças, conheçam os princípios básicos de saúde e nutrição das crianças, as vantagens da amamentação" (artigo 24, 2, "e"). A CPM/103 enuncia, ainda, o direito da mulher que labora a interromper seu trabalho especialmente para amamentar seu filho, durante um ou vários períodos, com duração determinada pela legislação nacional (artigo 5, item 1).

\footnotetext{
${ }^{29}$ Art. $5^{\circ}$, L: "às presidiárias serão asseguradas condições para que possam permanecer com seus filhos durante o período de amamentação;". BRAŞIL. Constituição da República Federativa do Brasil de 1988, cit.

${ }^{30}$ PIOVESAN, Flávia. op. cit.

${ }^{31}$ BRASIL. Ministério do Trabalho e Emprego. Convenção $n^{\circ}$ 103. Disponível em: <http://portal.mte. gov.br/legislacao/convencao-n-103.htm>. Acesso em: 11 jan. 2014.

${ }^{32}$ SÃO PAULO. Procuradoria Geral do Estado de São Paulo. Tratado Internacional. Disponível em: <http://www.pge.sp.gov.br/centrodeestudos/bibliotecavirtual/instrumentos/discrimulher.htm>. Acesso em: 11 jan. 2014.

${ }^{33}$ FUNDO DAS NAÇÕES UNIDAS PARA A INFÂNCIA. Convenção sobre os Direitos da Criança. Disponível em: <http://www.unicef.pt/docs/pdf_publicacoes/convencao_direitos_crianca2004.pdf>. Acesso em: 11 jan. 2014.
} 
O "tripé de fundamentalidade" formal do direito à amamentação completa-se com o artigo $6^{\circ}$, caput, que enuncia, entre os direitos fundamentais sociais, o direito à saúde e à maternidade, combinado ao artigo 227, caput, pelo qual se impõe à família, à sociedade e ao Estado o dever de garantir com absoluta prioridade, dentre outros, o direito da criança à vida, saúde e alimentação.

Materialmente, o direito à amamentação integra-se aos demais direitos humanos por ter como base o princípio da dignidade humana, núcleo dos direitos fundamentais ${ }^{(34)}$ e por força do caráter de universalidade e indivisibilidade dos direitos humanos, introduzido pela Declaração de 1948.(35),(36) Alinhada com essa nova concepção de direitos humanos, a CF/88 adotou "uma espécie de cláusula de abertura material"(37) pela qual o sistema constitucional de direitos fundamentais brasileiro abraça os direitos humanos enunciados em tratados internacionais decorrentes do regime e dos princípios adotados pela CF/88 (artigo $5^{\circ}$, parágrafo $2^{\circ}$ ), com força hierárquica constitucional, como visto (artigo $5^{\circ}$, parágrafo $3^{\circ}$ ). ${ }^{(38)}$

A previsão constitucional corrobora para o entendimento consolidado de fundamentalidade dos direitos que integram o corpus de concretização da dignidade da pessoa humana que, ao ser eleita como princípio fundamental da República Brasileira (artigo $1^{\circ}$, inciso III, da CF/88), se fincou como unidade valorativa do sistema de direitos fundamentais no Brasil. ${ }^{(39)}$

Noutro giro, o direito à amamentação, para além de seu caráter autônomo de fundamentalidade, é desdobramento claro dos direitos universais à vida, à saúde e à alimentação e, com absoluta prioridade, dos direitos da criança. A amamentação é essencial para promoção da saúde materna e infantil, de forma integral, e é a melhor opção nutricional, não só, mas notadamente,

\footnotetext{
${ }^{34}$ MIRANDA, Jorge. Manual de direito constitucional. 4. ed. Coimbra: Coimbra Ed., 2000. t. 4.

${ }^{35}$ BRASIL. Ministério da Justiça. Declaração Universal dos Direitos Humanos. Disponível em: <http:// portal.mj.gov.br/sedh/ct/legis_intern/ddh_bib_inter_universal.htm>. Acesso em: 11 jan. 2014.

${ }^{36}$ PIOVESAN, Flávia. op. cit.

${ }^{37}$ DALLARI, Sueli Gandolfi; NUNES JÚNIOR, Vidal Serrano. Direito sanitário. São Paulo: Ed. Verbatim, 2010. p. 35.

${ }^{38} \mathrm{Art.} 5^{\circ}, \S 2^{\circ}$ : "Os direitos e garantias expressos nesta Constituição não excluem outros decorrentes do regime e dos princípios por ela adotados, ou dos tratados internacionais em que a República Federativa do Brasil seja parte.". Art. $5^{\circ}, \S 3^{\circ}$ : "Os tratados e convenções internacionais sobre direitos humanos que forem aprovados, em cada Casa do Congresso Nacional, em dois turnos, por três quintos dos votos dos respectivos membros, serão equivalentes às emendas constitucionais.". BRASIL. Constituição da República Federativa do Brasil de 1988, cit.

${ }^{39}$ Id. Ibid.
} 
para comunidades que sofrem com o déficit social e econômico, de países em desenvolvimento. ${ }^{(40)}$

\section{Normas de proteção e promoção do direito à amamentação}

O direito à amamentação comporta uma complexidade de desdobramentos, vinculados, em primeira análise, ao próprio caráter de integralidade do direito à saúde e, ontologicamente, vincula-se à unicidade e indivisibilidade dos direitos humanos, cujo fundamento axiológico é a dignidade da pessoa humana.

Em harmonia com os diplomas internacionais de direitos humanos, o Brasil dispõe de um vasto arcabouço normativo de proteção à maternidade e ao direito à amamentação, complementadas por políticas públicas para concretização desse direito. A política de promoção, proteção e apoio à amamentação constitui uma das linhas prioritárias de cuidado do MS, cujo objetivo é reduzir a mortalidade infantil. Trata-se de um compromisso assumido pelo Brasil em nível internacional (Objetivos de Desenvolvimento do Milênio) e nacional, por meio do Pacto de Redução da Mortalidade Materna e Neonatal, Pacto pela Vida, Programa Mais Saúde. ${ }^{(41)}$

Em atenção aos princípios sanitários de descentralização e regionalização (artigo 198 da CF/88 e artigo $7^{\circ}$ da Lei $\left.n^{\circ} 8.080 / 90\right),{ }^{(42)}$ foi firmado o Termo de Compromisso entre o governo federal e os governos estaduais (estados da Região Nordeste e Amazônia Legal), para redução das desigualdades regionais.

\footnotetext{
${ }^{40}$ ARAÚJO, Maria de Fátima Moura de et al. op. cit.; MONTEIRO, Juliana Cristina dos Santos; GOMES, Flávia Azevedo; NAKANO, Ana Márcia Spanó. op. cit.; BAPTISTA, Gerson Henrique; ANDRADE, Adriano Herbert H. K. Gonçalves de; GIOLO, Suely Ruiz. Fatores associados à duração do aleitamento materno em crianças de famílias de baixa renda da região sul da cidade de Curitiba, Paraná, Brasil. Cadernos de Saúde Pública, Rio de Janeiro, v. 25, n. 3, p. 596-604, mar. 2009. SciELO Brasil. Disponível em: <http://www.scielo.br/scielo.php?script=sci_arttext\&pid=S0102-311X2009000300014 \&lng=pt\&nrm=iso>. Acesso em: 19 jan. 2014. doi: 10.1590/S0102-311X2009000300014; BARROS, Fernando $\mathrm{C}$ et al. Socioeconomic inequities in the health and nutrition of children in low/middle income countries. Revista de Saúde Pública, São Paulo, v. 44, n. 1, p. 1-16, fev. 2010. SciELO Brasil. Disponível em: <http://www.scielo.br/scielo.php?script=sci_arttext\&pid=S0034-89102010000100001\&lng=pt\&nr m=iso>. Acesso em: 19 jan. 2014. doi: 10.1590/S0034-89102010000100001.

${ }^{41}$ BRASIL. Ministério da Saúde. Secretaria de Atenção à Saúde Departamento de Ações Programáticas e Estratégicas. Pesquisa de Prevalência de Aleitamento Materno em Municípios brasileiros. Brasília: Ed. do Ministério da Saúde, 2010.

${ }^{42}$ Art. 70: "As ações e serviços públicos de saúde e os serviços privados contratados ou conveniados que integram o Sistema Único de Saúde (SUS), são desenvolvidos de acordo com as diretrizes previstas $\mathrm{n}^{\circ}$ art. 198 da Constituição Federal, obedecendo ainda aos seguintes princípios: (...) IX descentralização político-administrativa, com direção única em cada esfera de governo: a) ênfase na descentralização dos serviços para os municípios; b) regionalização e hierarquização da rede de serviços de saúde;". BRASIL. Lei n 8.080, de 19 de setembro de 1990. "Dispõe sobre as condições para a promoção, proteção e recuperação da saúde, a organização e o funcionamento dos serviços correspondentes e dá outras providências.”. Disponível em: < http://www.planalto.gov.br/ccivil_03/ leis//8080.htm>. Acesso em: 11 jan. 2014.
} 
A CF/88, em seu artigo 196, bem como a Lei $n^{\circ} 8.080 / 90$, em seu artigo $2^{\circ}$, reconhecem a saúde como direito universal e responsabilidade do Estado, a ser garantido por políticas sociais e econômicas, com vistas à redução do risco de doença e outros agravos, com acesso universal e igualitário às ações e serviços para sua promoção, proteção e recuperação. A Lei n 8.080/90 destaca, ainda, a alimentação como um dos fatores determinantes e condicionantes da saúde (artigo $3^{\circ}$ ) e prevê a alimentação e a nutrição como conteúdo essencial das políticas de saúde, nas esferas federal, estadual e municipal (artigos 13, 17 e18).

Tecendo a rede de cuidados, no espaço normativo infralegal, o MS aprovou, por meio da Portaria MS/GM n².607/04, ${ }^{(43)}$ o Plano Nacional de Saúde (PNS), que prevê (tópico 4), como uma das linhas de cuidado na atenção integral à saúde da criança, a amamentação, alimentação saudável e nutrição adequada. Quanto à promoção da amamentação, a ação dar-se-á em articulação com os Ministérios da Previdência Social e do Trabalho e Emprego, para estender o período de licença e do auxílio-maternidade para seis meses após o parto, de modo a favorecer o prolongamento da amamentação, independentemente do tempo de contribuição da trabalhadora para o Instituto Nacional de Seguro Social (INSS).

Por força do aumento expressivo da população feminina hoje inserida no mercado informal de trabalho, a portaria busca garantir, especificamente às mães trabalhadoras não contribuintes da Previdência Social, os proventos no valor de um salário mínimo, desde que a unidade de saúde de referência forneça comprovação do aleitamento materno (Portaria MS/GM n².607/04).

\section{Direito à amamentação de mulheres privadas de liberdade}

A CF/88 é a primeira constituição brasileira a prever, expressamente, o direito à amamentação. Assim, em seu artigo $5^{\circ}$, inciso L, garante o direito à amamentação em condições adequadas, para a mulher privada de liberdade. Infraconstitucionalmente, a Lei de Execuções Penais de 1984 (Lei nº 7.210 - LEP)(44) garante à condenada, à mulher submetida à medida de segurança, à presa provisória e à egressa "berçário, onde as condenadas possam cuidar de seus filhos, inclusive amamentá-los, no mínimo, até 6 (seis) meses de idade" (artigo 82, parágrafo $2^{\circ}$ ).

A LEP prevê também o atendimento qualificado à mulher e à criança, de acordo com as diretrizes adotadas pela legislação educacional e em unidades autônomas, com horário de funcionamento que garanta a melhor assistência à criança e à sua responsável (artigo 98, parágrafo único, incisos I e II).

\footnotetext{
${ }^{43}$ BRASIL. Ministério da Saúde. Portaria n².607/GM, de 10 de dezembro de 2004. "Aprova o Plano Nacional de Saúde/PNS - Um Pacto pela Saúde no Brasil.”. Disponível em: <http://dtr2001.saude. gov.br/sas/PORTARIAS/Port2004/Gm/GM-2607.htm>. Acesso em: 19 jan. 2014.

${ }^{44}$ BRASIL. Lei $n^{\circ} 7.210$, de 11 de julho de 1984. "Institui a Lei de Execução Penal.". Disponível em: <http://www.planalto.gov.br/ccivil_03/leis/l7210.htm>. Acesso em: 19 jan. 2014.
} 


\section{Trabalho e amamentação}

A CF/88 garante, no seu artigo $7^{\circ}$, licença maternidade por 120 dias à mulher que trabalha, além de licença paternidade, nos termos da lei, sem prejuízo de emprego ou salário. A Consolidação das Leis do Trabalho $(C L T)^{(45)}$ reitera o texto constitucional, no seu artigo 392. Na tecedura dessa rede jurídica de cuidados, a Lei $n^{\circ} 11.770 / 08,{ }^{(46)}$ criou o Programa Empresa Cidadã, com o objetivo de prorrogar a licença-maternidade mediante concessão de incentivo fiscal.

Apesar de não tratar propriamente sobre amamentação, a Lei 11.770/08 harmoniza-se com a recomendação da OMS, por possibilitar a extensão do aleitamento materno, promovendo maior proteção à saúde da criança e os vínculos entre esta e a mãe. Noutro giro, a necessidade de trabalhar fora do lar é, frequentemente, considerada como fator determinante para o desmame precoce. ${ }^{(47)}$

Também a CLT, no seu artigo 389, parágrafos $1^{\circ}$ e $2^{\circ}$, c/c artigo 400, obriga toda empresa em que trabalharem pelo menos 30 mulheres, com idade superior a 16 anos, a disponibilizar local apropriado para que as empregadas guardem, sob vigilância e assistência, os seus filhos no período da amamentação. Esses espaços devem ser equipados, no mínimo, com um berçário, uma saleta de amamentação, uma cozinha dietética e uma instalação sanitária. É também garantida à mãe nos primeiros seis meses após o parto, conforme o artigo 396 da CLT, o direito a dois descansos especiais, de meia hora cada um, durante a jornada de trabalho. No seu parágrafo único, possibilita a extensão do período de amamentação, quando necessário à saúde da criança.

Esse direcionamento é fundamental, vez que, de acordo com Rea, ${ }^{(48)}$ uma das principais razões do desmame precoce é a separação da mãe de seu filho, por força da volta da mulher ao trabalho fora do lar. As mulheres, em geral, têm o desejo de amamentar e experimentam grande expectativa em relação a isso. O desejo é reforçado pela confiança na continuidade do aleitamento, mesmo após o retorno

\footnotetext{
${ }^{45}$ BRASIL. Decreto-Lei $n^{\circ} 5.452$, de $1^{\circ}$ de maio de 1943 . "Aprova a Consolidação das Leis do Trabalho.”. Disponível em: < http://www.planalto.gov.br/ccivil_03/decreto-lei/Del5452compilado. htm>. Acesso em> 19 jan. 2014.

${ }^{46}$ BRASIL. Lei $n^{\circ} 11.770$, de 9 de setembro de 2008. "Cria o Programa Empresa Cidadã, destinado à prorrogação da licença-maternidade mediante concessão de incentivo fiscal, e altera a Lei $\mathrm{n}^{\circ}$ 8.212, de 24 de julho de 1991.”. Disponível em: < http://www.planalto.gov.br/ccivil_03/_ato20072010/2008/lei/l11770.htm>. Acesso em: 19 jan. 2014.

${ }^{47}$ FALEIROS, Francisca Teresa Veneziano; TREZZA, Ercília Maria Carone; CARANDINA, Luana. Aleitamento materno: fatores de influência na sua decisão e duração. Revista de Nutrição, Campinas, v. 19, n. 5, p. 623-630, out. 2006. SciELO Brasil. Disponível em: <http://www.scielo.br/ scielo.php?script=sci_arttext\&pid=S1415-52732006000500010\&lng=pt\&nrm=iso>. Acesso em: 19 jan. 2014. doi: 10.1590/S1415-52732006000500010.

${ }^{48}$ REA, Marina Ferreira et al. Possibilidades e limitações da amamentação entre mulheres trabalhadoras formais. Revista de Saúde Pública, São Paulo, v. 31, n. 2, p. 149-156, abr. 1997. SciELO Brasil. Disponível em <http://www.scielo.br/scielo.php?script=sci_arttext\&pid=S0034$89101997000200008 \& \mathrm{lng}=p t \& n r m=i s o>$. Acesso em: 19 jan. 2014. doi: 10.1590/S003489101997000200008.
} 
ao trabalho, e a existência de creches no local de trabalho aparece como elemento relevante para a manutenção da amamentação, ao final da licença-maternidade. ${ }^{(49)}$

Em âmbito infralegal, a Agência Nacional de Vigilância Sanitária (Anvisa) aprovou, por meio da Portaria MS/ANVISA n 193/10, a nota técnica conjunta $\mathrm{n}^{\circ}$ 01/2010 Anvisa e MS, ${ }^{(50)}$ para orientar a instalação de salas de apoio à amamentação em empresas públicas ou privadas e a fiscalização desses ambientes pelas vigilâncias sanitárias locais. Condições adequadas de amamentação no local de trabalho estão entre os fatores favoráveis à decisão das mães de continuarem amamentando, quando retornam ao trabalho. ${ }^{(51)}$

\section{Alojamento conjunto}

A CF/88, em seu artigo 227, determina que deve ser assegurado pela família, pelo Estado e pela sociedade, com absoluta prioridade, o direito à vida, à saúde e à alimentação da criança. Assim, a Lei $n^{\circ} 8.069 / 90,{ }^{(52)}$ que institui o Estatuto da Criança e do Adolescente (ECA), costurando mais um ponto nessa rede de cuidado, impõe ao poder público, às instituições e aos empregadores que propiciem condições adequadas ao aleitamento materno, inclusive aos filhos de mães submetidas a medida privativa de liberdade (artigo $9^{\circ}$ ). Nesse sentido, as ações de responsabilidade por ofensa aos direitos da criança, dessa natureza, regem-se por essa lei (artigo 208, inciso VI).

O ECA obriga, ainda, os hospitais e demais estabelecimentos de atenção à saúde de gestantes, públicos e particulares, a manter alojamento conjunto, o que possibilita ao neonato a permanência junto à mãe e estimula a amamentação, nos primeiros momentos de vida (artigo $10^{\circ}$, inciso $\mathrm{V}$ ).

De acordo com Marques e Melo, ${ }^{(53)}$ com o propósito de humanizar o nascimento e reforçar os vínculos entre o bebê e a mãe, e promover a amamentação, o pesquisador Edith Jackson, criou o experimento conhecido como Projeto Alojamento Conjunto, inaugurado, em 1946, no Grace New Haven Hospital.

\footnotetext{
${ }^{49}$ OSIS, Maria José Duarte et al. Aleitamento materno exclusivo entre trabalhadoras com creche no local de trabalho. Revista de Saúde Pública, São Paulo, v. 38, n. 2, p. 172-179, abr. 2004. SciELO Brasil. Disponível em: <http://www.scielo.br/scielo.php?script=sci_arttext\&pid=S0034$89102004000200004 \& \operatorname{lng}=p t \& n r m=i s o>$. Acesso em: 19 jan. 2014. doi: 10.1590/S003489102004000200004

${ }^{50}$ NORMAS LEGAIS. Portaria MS/Anvisa n 193, de 23 de fevereiro de 2010. Disponível em: < http:// www.normaslegais.com.br/legislacao/portariaanvisa193_2010.htm>. Acesso em: 19 jan. 2014.

${ }^{51}$ FALEIROS, Francisca Teresa Veneziano; TREZZA, Ercília Maria Carone; CARANDINA, Luana. op. cit.

${ }^{52}$ BRASIL. Lei n 8.069 , de 13 de julho de 1990. "Dispõe sobre o Estatuto da Criança e do Adolescente e dá outras providências". Disponível em: <http://www.planalto.gov.br/ccivil_03/leis//8069.htm>. Acesso em: 19 jan. 2014.

${ }^{53}$ MARQUES, Maria Cecília dos Santos; MELO, Adriana de Medeiros. Amamentação no alojamento conjunto. Revista CEFAC, São Paulo, v. 10, n. 2, p. 261-271, 2008. SciELO Brasil. Disponível em: $<$ http://www.scielo.br/scielo.php?script=sci_arttext\&pid=S1516-18462008000200017\&lng=pt\&nrm =iso>. Acesso em: 19 jan. 2014. doi: 10.1590/S1516-18462008000200017.
} 
Em 1993, com o objetivo de incentivar a lactação e amamentação, estreitar e fortalecer o relacionamento entre a mãe e a criança e diminuir o risco de infecção hospitalar, complicações maternas e neonatais, o MS aprovou, por meio da Portaria GM/MS no 1.016, ${ }^{(54)}$ as Normas Básicas para a implantação do sistema Alojamento Conjunto. A portaria obriga os hospitais e maternidades vinculadas ao SUS a implantarem "alojamento conjunto total", isto é, aquele em que mãe e criança permanecem juntas, em um mesmo quarto, 24 horas por dia, durante sua hospitalização pós-parto, sendo-Ihes prestados todos os cuidados assistenciais e de orientação para promoção da saúde e do vínculo materno-infantil.

Finalmente, a Resolução da Diretoria Colegiada n 36/08 (RDC 36/2008) $)^{(55)}$ prevê que os Serviços de Atenção Obstétrica e Neonatal devem garantir a adoção de alojamento conjunto desde o nascimento (tópico 5.6.4), devendo estimular a amamentação desde o ambiente do parto e, na assistência ao puerpério, promover o aleitamento materno sob livre demanda e garantir que a mulher, quando em uso de medicamentos ou portadora de patologias, tenha orientação clara e segura, e apoio psicológico de acordo com suas necessidades, caso esses medicamentos ou patologias interfiram com a amamentação (RDC 36/08, tópicos 5.6.7, 5.6.7.5, 5.6.8.1 e 5.6.8.5).

Essa é uma ação que segue o princípio de humanização dos serviços do SUS, com valorização da dimensão subjetiva e social em todas as práticas de atenção e gestão. ${ }^{(56)}$ Não é só uma ação de promoção da saúde, mas de respeito à dignidade humana, à cidadania e à mulher.

$\mathrm{Na}$ linha de cuidados para redução da mortalidade materna e infantil, pela promoção da amamentação, o MS institui, no âmbito do SUS, a Rede Amamenta Brasil, ${ }^{(57)}$ para encorajamento da amamentação, pelas equipes de saúde, para aumentar sua precocidade e duração (Portaria MS/GM n².799/08). Instituiu, também, a Rede Norte-Nordeste de Saúde Perinatal, parte integrante da Rede

\footnotetext{
${ }^{54}$ BRASIL. Ministério da Saúde. Portaria n 1.016, de 26 de agosto de 1993. Disponível em: < http:// pnass.datasus.gov.br/documentos/normas/40.pdf>. Acesso em: 19 jan. 2014.

${ }^{55}$ Resolução-RDC no 36, de 3 de junho de 2008. "Dispõe sobre Regulamento Técnico para Funcionamento dos Serviços de Atenção Obstétrica e Neonatal". Diario Oficial da União. Seção 1, n. 105, 4 de junho de 2008. Disponível em: < http://www.anvisa.gov.br/divulga/ noticias/2008/040608_1_rdc36.pdf>. Acesso em: 19 jan. 2014.

${ }^{56}$ BRASIL. Ministério da Saúde. Secretaria-Executiva. Núcleo Técnico da Política Nacional de Humanização. HumanizaSUS: Política Nacional de Humanização: a humanização como eixo norteador das práticas de atenção e gestão em todas as instâncias do SUS. Ministério da Saúde, Secretaria-Executiva, Núcleo Técnico da Política Nacional de Humanização. - Brasília: Ministério da Saúde, 2004. 20 p. (Série B. Textos Básicos de Saúde).

${ }^{57}$ BRASIL. Ministério da Saúde. Secretaria de Atenção à Saúde. Área Técnica de Saúde da Criança e Aleitamento Materno. Rede Amamenta Brasil: os primeiros passos (2007-2010) / Ministério da Saúde. Secretaria de Atenção à Saúde. Área Técnica de Saúde da Criança e Aleitamento Materno. - Brasília: Ministério da Saúde, 2011. Disponível em: < http://bvsms.saude.gov.br/bvs/publicacoes/ rede_amamenta_brasil_primeiros_passos.pdf>. Acesso em: 28 jan. 2014.
} 
Amamenta Brasil, mas cuja ação é direcionada ao Norte-Nordeste (Portaria $\left.\mathrm{MS} / \mathrm{GM} \mathrm{n}{ }^{\circ} 2.800 / 08\right){ }^{(58)}$

Iniciativa que se alinhou no incentivo à prática do cuidado foi a da habilitação do Hospital Amigo da Criança no SUS, em atenção ao compromisso assumido pelo Brasil na Reunião de Cúpula em Favor da Infância, realizada de 1990. O objetivo é promover e proteger a amamentação, garantindo que os hospitais atendam às normas da Portaria MS/SAS 756/04, ${ }^{(59)}$ que tem como exigência para habilitação, dentre outras, a comprovação do cumprimento à Norma Brasileira de Comercialização de Alimentos para Lactentes e Crianças na Primeira Infância; possuir comitê de investigação de óbitos maternos, infantis e fetais, implantado e atuante; realizar os Dez Passos para o Sucesso do Aleitamento Materno, proposto pela OMS e pelo Fundo das Nações Unidas para a Infância. ${ }^{(60)}$

Vannuchi et al (61) demonstram que a iniciativa Hospital Amigo da Criança teve um impacto positivo sobre os índices de amamentação durante a internação neonatal e nos 6 primeiros meses de vida, com aumento expressivo do percentual de crianças em aleitamento materno exclusivo: de 1,9\%, em 1994, para 41,7\%, em 1998.

\section{A comercialização de substitutos do leite materno}

Reconhecendo a necessidade de regular e monitorar a atuação comercial abusiva que, por meio de técnicas de marketing, estimula a interrupção precoce de amamentação, ${ }^{(62)}$ o MS e a Anvisa editaram a Portaria GM/MS 2.051/01 e as Resoluções Anvisa RDC nos 221 e 222. Essas normas infralegais visam salvaguardar a amamentação da propaganda indiscriminada de produtos, estabelecendo as normas para comercialização de alimentos a lactentes e crianças de primeira infância, bicos, chupetas e mamadeiras.

\footnotetext{
${ }^{58}$ BRASIL. Ministério da Saúde. Portaria n 2.800, de 18 de novembro de 2008. "Institui, no âmbito do Sistema Único de Saúde - SUS -, a Rede Norte-Nordeste de Saúde Perinatal.”. Disponível em: <http:// dtr2001.saude.gov.br/sas/PORTARIAS/Port2008/GM/GM-2800.htm>. Acesso em: 19 jan. 2014.

${ }^{59}$ BRASIL. Ministério da Saúde. Portaria $n^{\circ} 756$, de 16 de dezembro de 2004. Disponível em: < http:// dtr2001.saude.gov.br/sas/PORTARIAS/Port2004/PT-756.htm>. Acesso em: 19 jan. 2014.

${ }^{60}$ LAMOUNIER, J. A. Experiência iniciativa Hospital Amigo da Criança. Revista da Associação Médica Brasileira, São Paulo, v. 44, n. 4, p. 319-324, dez. 1998. SciELO Brasil. Disponível em: $<$ http://www.scielo.br/scielo.php?script=sci_arttext\&pid=S0104-42301998000400011\&lng=pt\&nrm =iso>. Acesso em: 19 jan. 2014. doi: 10.1590/S0104-42301998000400011.

${ }^{61}$ VANNUCHI, Marli T Oliveira et al. Iniciativa Hospital Amigo da Criança e aleitamento materno em unidade de neonatologia. Revista de Saúde Pública, São Paulo, v. 38, n. 3, p. 422-428, jun. 2004. SciELO Brasil. Disponível em <http://www.scielo.br/scielo.php?script=sci_arttext\&pid=S0034$89102004000300013 \&$ lng=pt\&nrm=iso $>$. Acesso em: 19 jan. 2014. doi: 10.1590/S003489102004000300013.

${ }^{62}$ BRASIL. Ministério da Saúde. Secretaria de Atenção à Saúde. Departamento de Ações Programáticas Estratégicas. A legislação e o marketing de produtos que interferem na amamentação: um guia para o profissional de saúde. Ministério da Saúde, Secretaria de Atenção à Saúde, Departamento de Ações Programáticas Estratégicas. - Brasília: Editora do Ministério da Saúde, 2009-A. 114 p. (Série A. Normas e Manuais Técnicos).
} 
Em 2006, a Lei $n^{\circ} 11.265^{(63)}$ veio regulamentar a comercialização desses alimentos e também dos produtos de puericultura. A lei estabelece como objetivo a proteção ao aleitamento materno exclusivo nos primeiros 6 meses de idade da criança e o incentivo à amamentação até os 2 anos de idade, após a introdução de novos alimentos na dieta das crianças (artigo $1^{\circ}$, incisos I e III).

No artigo 19, como estratégia de proteção à saúde e à amamentação, determina que todo material educativo e técnico-científico que trate de alimentação de lactentes e de crianças de primeira infância deverá informar sobre os benefícios e a superioridade da amamentação (inciso l); orientação sobre a alimentação adequada com incentivo à continuidade da amamentação até 2 anos de idade ou mais (inciso II); os efeitos negativos da substituição da amamentação, por outros alimentos, destacando a dificuldade de preparo e higienização dos alimentos (inciso III); e "as implicações econômicas da opção pelos alimentos usados em substituição ao leite materno ou humano, ademais dos prejuízos causados à saúde do lactente pelo uso desnecessário ou inadequado de alimentos artificiais" (inciso IV).

No seu artigo 21, a Lei $n^{\circ}$ 11.265/06 enuncia, também, que constitui competência prioritária dos profissionais de saúde estimular e divulgar a prática do aleitamento materno exclusivo até os 6 (seis) meses e continuado até os 2 anos de idade ou mais.

A ênfase dada pela legislação brasileira reflete a preocupação, nacional e internacional, por parte da comunidade científica e dos Estados, com os riscos do desmame precoce e a relação entre a comercialização de alimentos infantis e o declínio na amamentação. ${ }^{(64)}$ Com o reconhecimento da necessidade de se controlar esse fenômeno, como estratégia de proteção e promoção à saúde da criança e da lactante, a OMS e a Unicef aprovaram em 1981 o Código Internacional de Comercialização de Substitutos do Leite Materno. ${ }^{(65),(66)}$

A iniciação do consumo de alimentos complementares acontece em período bem precoce da vida, oferecidos em quantidade insuficiente para suprir as recomendações nutricionais, particularmente de micronutrientes. ${ }^{(67)} \mathrm{A}$ comercialização indevida de substitutos do leite materno põe em risco a prática da amamentação e, portanto, favorece o aumento dos índices de desnutrição,

\footnotetext{
${ }^{63}$ BRASIL. Lei $n^{\circ} 11.265$, de 3 de janeiro de 2006. "Regulamenta a comercialização de alimentos para lactentes e crianças de primeira infância e também a de produtos de puericultura correlatos.". Disponível em: < http://www.planalto.gov.br/ccivil_03/_Ato2004-2006/2006/Lei/L11265.htm>. Acesso em: 11 jan. 2014.

${ }^{64} \mathrm{Id}$. Ibid.

${ }^{65}$ Disponível em: < http://www.fiocruz.br/redeblh/media/ams34_cod.pdf>. Acesso em: 19 jan. 2014.

${ }^{66}$ REA, Marina Ferreira. Substitutos do leite materno: passado e presente. Revista de Saúde Pública, São Paulo, v. 24, n. 3, p. 241-249, jun. 1990. SciELO Brasil. Disponível em <http://www.scielo.br/ scielo.php?script=sci_arttext\&pid=S0034-89101990000300011\&lng=pt\&nrm=iso>. Acesso em: 11 jan. 2014. doi: 10.1590/S0034-89101990000300011.

${ }^{67}$ OLIVEIRA, Lucivalda Pereira Magalhães de et al. Alimentação complementar nos primeiros dois anos de vida. Revista de Nutrição, Campinas, v. 18, n. 4, p. 459-469, ago. 2005. SciELO Brasil. Disponível em: <http://www.scielo.br/scielo.php?script=sci_arttext\&pid=S1415-52732005000400002\&lng=pt\& nrm=iso >. Acesso em: 19 jan. 2014. doi: 10.1590/S1415-52732005000400002.
} 
doenças e mortalidade infantil, especialmente em países em desenvolvimento, onde fatores sociais, econômicos e culturais favorecem o adoecimento infantil e a morbimortalidade. As restrições à comercialização, a informação adequada às mães e o estímulo à amamentação, como regra na alimentação de crianças com até 2 anos de idade, têm importância central na promoção da saúde materna e infantil. ${ }^{(68)}$

\section{Considerações Finais}

A família desempenha um papel central na promoção e perpetuação da prática da amamentação, como linha de cuidado e estratégia de garantia da saúde materno-infantil. Os saberes acumulados pela família, especialmente pelas mulheres que já vivenciaram a maternidade, são de importância nuclear nesse processo e cabe ao Estado, além de implementar políticas de garantia do direito à amamentação, reconhecer e restabelecer o lugar da família nessas ações.

A garantia do direito à amamentação da criança impõe ao Estado, igualmente, a obrigação de prover condições para que o aleitamento se dê, com segurança, higiene e dignidade, resguardado de todas as formas de violência e discriminação contra a nutriz.

O Brasil conta com um amplo arcabouço normativo de proteção direta e indireta à amamentação. A CF/88 inovou, no sistema jurídico-constitucional brasileiro, ao enunciar expressamente a amamentação como direito fundamental e ao conferir à saúde o caráter universal e prestacional. A incorporação dos diplomas internacionais de direitos humanos, com força constitucional e aplicabilidade imediata, bem como a definição da dignidade humana como núcleo do sistema de direitos fundamentais no Brasil, são marcos dessa rede de proteção legal à amamentação.

Em âmbito constitucional, legal e infralegal, o sistema brasileiro busca proteger, de forma transversal, o direito à amamentação. Ele se constrói em um sistema de proteção universal, como direito fundamental, com proteção à mulher que labora e à maternidade como um todo, reconhecendo o direito à saúde e alimentação da criança e da mãe, buscando viabilizar concretamente esse direito, através de regulamentações e políticas públicas.

\footnotetext{
${ }^{68}$ REA, Marina Ferreira; TOMA, Tereza Setsuko. Proteção do leite materno e ética. Revista de Saúde Pública, São Paulo, v. 34, n. 4, p. 388-395, ago. 2000. SciELO Brasil. Disponível em: <http:// www.scielo.br/scielo.php?script=sci_arttext\&pid=S0034-89102000000400012\&lng=pt\&nrm=iso $>$. Acesso em: 19 jan. 2014. doi: 10.1590/S0034-89102000000400012; ARAÚJO, Maria de Fátima Moura de et al. Avanços na norma brasileira de comercialização de alimentos para idade infantil. Revista de Saúde Pública, São Paulo, v. 40, n. 3, p. 513-520, jun. 2006. SciELO Brasil. Disponível em: <http://www.scielosp.org/scielo.php?script=sci_arttext\&pid=S0034-89102006000300021\&lng= pt\&nrm=iso >. Acesso em: 19 jan. 2014. doi: 10.1590/S0034-89102006000300021.
} 
A atuação do poder público, nesse particular, merece destaque pelo seu caráter integral e por reconhecer a importância da amamentação, inclusive, regulando e restringindo o comércio de fórmulas alimentares que substituem o leite materno, interrompendo de forma precoce a amamentação.

Essas ações, contudo, não devem se limitar ao espaço da gestão e hospitalar, sendo necessária a continuidade de políticas educacionais, como a Semana Mundial da Amamentação do MS - que ocorre anualmente de $1^{\circ}$ a 7 de agosto, desde 1992 - para divulgar as vantagens e a importância da amamentação. Unidas a essa, outras ações são necessárias, com foco na conscientização das mães, familiares, profissionais de saúde e gestores, sobre a importância e os benefícios sociais, econômicos e à saúde, da amamentação.

Considerando as novas configurações familiares e os diferentes papéis dos seus membros quanto à necessária rede de cuidado da criança, o incentivo à amamentação envolve, além da participação direta da nutriz, a do pai, das avós e os integrantes da dinâmica da família, seja qual for o seu desenho de conjugalidade. $O$ direito à amamentação constitui, pois, um direito ao cuidado em família, expressão de acolhimento e de afirmação do desenvolvimento do novo membro recebido na instância afetiva. Cabe ao Estado, como corresponsável pela criança, manter a garantia desse cuidado tanto no plano das políticas quanto no plano legislativo.

\section{Referências}

AITH, Fernando. Curso de direito sanitário: a proteção do direito à saúde no Brasil. São Paulo: Quatier Latin, 2007.

ALMEIDA, Jag; NOVAK, FR. Amamentação: um híbrido natureza-cultura Jornal de Pediatria, v. 80, n. 5, 2004.

ARAÚJO, Maria de Fátima Moura de et al. Avanços na norma brasileira de comercialização de alimentos para idade infantil. Revista de Saúde Pública, São Paulo, v. 40, n. 3, p. 513-520, jun. 2006. SciELO Brasil. Disponível em: <http://www.scielosp.org/scielo.php?script=sci_arttext\&pid=S0034$89102006000300021 \& \mathrm{lng}=\mathrm{pt \& nrm}=\mathrm{iso}>$. Acesso em: 19 jan. 2014. doi: 10.1590/S0034-89102006000300021.

et al. Custo e economia da prática do aleitamento materno para a família. Revista Brasileira de Saúde Materno Infantil, Recife, v. 4, n. 2, p. 135141, jun. 2004. SciELO Brasil. Disponível em: <http://www.scielo.br/scielo. php?script=sci_arttext\&pid=S1519-38292004000200003\&lng=pt\&nrm=iso $>$. Acesso em: 19 jan. 2014. doi: 10.1590/S1519-38292004000200003. 
BAPTISTA, Gerson Henrique; ANDRADE, Adriano Herbert H. K. Gonçalves de; GIOLO, Suely Ruiz. Fatores associados à duração do aleitamento materno em crianças de famílias de baixa renda da região sul da cidade de Curitiba, Paraná, Brasil. Cadernos de Saúde Pública, Rio de Janeiro, v. 25, n. 3, p. 596604, mar. 2009. SciELO Brasil. Disponível em: <http://www.scielo.br/scielo. php?script=sci_arttext\&pid=S0102-311X2009000300014\&Ing=pt\&nrm=iso > . Acesso em: 19 jan. 2014. doi: 10.1590/S0102-311X2009000300014.

BARBOSA, Marina Borelli; PALMA, Domingos. Fatores de risco associados ao desmame precoce e ao período de desmame em lactentes matriculados em creches. Revista Paulista de Pediatria, São Paulo, v. 27, n. 3, set. 2009. SciELO Brasil. Disponível em: <http://www.scielo.br/scielo.php?script=sci_ arttext\&pid=S0103-05822009000300007\&lng=pt\&nrm=iso>. Acesso em: 19 jan. 2014. doi: 10.1590/S0103-05822009000300007.

BARROS, Fernando $\mathrm{C}$ et al. Socioeconomic inequities in the health and nutrition of children in low/middle income countries. Revista de Saúde Pública, São Paulo, v. 44, n. 1, p. 1-16, fev. 2010. SciELO Brasil. Disponível em: <http://www.scielo. br/scielo.php?script=sci_arttext\&pid=S0034-89102010000100001\&lng=pt\&nr $\mathrm{m}=$ iso $>$. Acesso em: 19 jan. 2014. doi: 10.1590/S0034-89102010000100001.

BONAVIDES, Paulo. Curso de direito constitucional. 21. ed. São Paulo: Malheiros Ed., 2007.

BOWLBY, John. Apego e perda: apego, a natureza do vínculo. 2. ed. São Paulo: Martins Fontes, 1990. v. 1.

BRASIL. Ministério da Saúde. Secretaria de Atenção à Saúde. Área Técnica de Saúde da Criança e Aleitamento Materno. Rede Amamenta Brasil: os primeiros passos (2007-2010) / Ministério da Saúde. Brasília: Ed. do Ministério da Saúde, 2011. Disponível em: < http://bvsms.saude.gov.br/bvs/publicacoes/ rede_amamenta_brasil_primeiros_passos.pdf>. Acesso em: 28 jan. 2014.

Ministério da Saúde. Secretaria de Atenção à Saúde. Departamento de Ações Programáticas e Estratégicas. Pesquisa de Prevalência de Aleitamento Materno em Municípios brasileiros. Brasília: Ed. do Ministério da Saúde, 2010.

Ministério da Saúde. Secretaria de Atenção à Saúde. Departamento de Atenção Básica. Saúde da criança: nutrição infantil. Aleitamento materno e alimentação complementar. Ministério da Saúde, Secretaria de Atenção à Saúde, Departamento de Atenção Básica. - Brasília: Ed. do Ministério da Saúde, 2009. 112 p. (Série A. Normas e Manuais Técnicos) (Cadernos de Atenção Básica, n. 23). 
BRASIL. Ministério da Saúde. Secretaria de Atenção à Saúde. Departamento de Ações Programáticas Estratégicas. A legislação e o marketing de produtos que interferem na amamentação: um guia para o profissional de saúde. Ministério da Saúde, Secretaria de Atenção à Saúde, Departamento de Ações Programáticas Estratégicas. - Brasília: Editora do Ministério da Saúde, 2009. 114 p. (Série A. Normas e Manuais Técnicos).

Ministério da Saúde. Secretaria de Política de Saúde. Organização Pan Americana da Saúde. Guia alimentar para crianças menores de dois anos. Secretaria de Políticas de Saúde, Organização Pan Americana da Saúde. Brasília: Ministério da Saúde, 2002.

. Ministério da Saúde. Secretaria-Executiva. Núcleo Técnico da Política Nacional de Humanização. HumanizaSUS: Política Nacional de Humanização: a humanização como eixo norteador das práticas de atenção e gestão em todas as instâncias do SUS. Ministério da Saúde, Secretaria-Executiva, Núcleo Técnico da Política Nacional de Humanização. - Brasília: Ministério da Saúde, 2004. 20 p. (Série B. Textos Básicos de Saúde).

BUSSAB, V. S. R. A família humana vista da perspectiva etológica: natureza ou cultura? Interação, Curitiba, v. 4, p. 9-22, 2000.

CANOTILHO, J. J. Gomes. Direito constitucional e teoria da Constituição. 3. ed. Coimbra: Almedina, 1998.

DALLARI, Dalmo de Abreu. Direitos humanos e cidadania. 10. ed. São Paulo: Moderna, 2004.

DALLARI, Sueli Gandolfi; NUNES JÚNIOR, Vidal Serrano. Direito sanitário. São Paulo: Ed. Verbatim, 2010.

FALEIROS, Francisca Teresa Veneziano; TREZZA, Ercília Maria Carone; CARANDINA, Luana. Aleitamento materno: fatores de influência na sua decisão e duração. Revista de Nutrição, Campinas, v. 19, n. 5, p. 623-630, out. 2006. SciELO Brasil. Disponível em: <http://www.scielo.br/scielo.php?script=sci_ arttext\&pid=S1415-52732006000500010\&lng=pt\&nrm=iso >. Acesso em: 19 jan. 2014. doi: 10.1590/S1415-52732006000500010.

FLEURY, Sônia. A reforma sanitária: processo histórico. In: BANCO INTERNACIONAL DE DESENVOLVIMENTO (BID). A construção da reforma sanitária no Brasil e os desafios para os gestores. 2. ed. INDES, 2009.

GALVÃO, D. M. P. G. Amamentação bem sucedida: alguns fatores determinantes. Loures: Lusociência Ed. Técnicas e Cientificas, 2006.

HABERMAS, Jürgen. Mudança estrutural na esfera pública: investigações quanto a uma categoria da sociedade burguesa. 2. ed. Rio de Janeiro: Tempo Brasileiro, 2003. 
LAMOUNIER, J. A. Experiência iniciativa Hospital Amigo da Criança. Revista da Associação Médica Brasileira, São Paulo, v. 44, n. 4, p. 319-324, dez. 1998. SciELO Brasil. Disponível em: <http://www.scielo.br/scielo.php?script=sci_ arttext\&pid=S0104-42301998000400011\&lng=pt\&nrm=iso >. Acesso em: 19 jan. 2014. doi: 10.1590/S0104-42301998000400011.

MARQUES, Emanuele Souza et al. A influência da rede social da nutriz no aleitamento materno: o papel estratégico dos familiares e dos profissionais de saúde. Ciência e Saúde Coletiva, Rio de Janeiro, v. 15, suppl. 1, p. 1391-1400, 2011. SciELO Brasil. Disponível em: <http://www.scielo.br/scielo.php?script=sci arttext\&pid=S1413-81232010000700049\&lng=pt\&nrm=iso >. Acesso em: 19 jan. 2014. doi: 10.1590/S1413-81232010000700049.

MARQUES, Maria Cecília dos Santos; MELO, Adriana de Medeiros. Amamentação no alojamento conjunto. Revista CEFAC, São Paulo, v. 10, n. 2, p. 261-271, 2008. SciELO Brasil. Disponível em: <http://www.scielo.br/scielo. php?script=sci_arttext\&pid=S1516-18462008000200017\&lng=pt\&nrm=iso $>$. Acesso em: 19 jan. 2014. doi: 10.1590/S1516-18462008000200017.

MIRANDA, Jorge. Manual de direito constitucional. 4. ed. Coimbra: Coimbra Ed., 2000. t. 4.

MONTEIRO, Juliana Cristina dos Santos; GOMES, Flávia Azevedo; NAKANO, Ana Márcia Spanó. Amamentação e o seio feminino: uma análise sob a ótica da sexualidade e dos direitos reprodutivos. Texto Contexto - enferm., Florianópolis, v. 15, n. 1, p. 146-150, mar. 2006. SciELO Brasil. Disponível em: <http://www. scielo.br/scielo.php?script=sci_arttext\&pid=S0104-07072006000100018\&lng=pt \&nrm=iso $>$. Acesso em: 19 jan. 2014. doi: 10.1590/S0104-07072006000100018.

NAKANO, Ana Márcia Spanó et al. Women's social space and the reference for breastfeeding practice. Revista Latino-Americana de Enfermagem, Ribeirão Preto, v. 15, n. 2, p. 230-238, abr. 2007. SciELO Brasil. Disponível em: <http://www. scielo.br/scielo.php?script=sci_arttext\&pid=S0104-11692007000200007\&lng=pt \&nrm=iso >. Acesso em: 19 jan. 2014. doi: 10.1590/S0104-11692007000200007.

OLIVEIRA, Lucivalda Pereira Magalhães de et al. Alimentação complementar nos primeiros dois anos de vida. Revista de Nutrição, Campinas, v. 18, n. 4, p. 459-469, ago. 2005. SciELO Brasil. Disponível em: <http://www.scielo.br/scielo. php?script=sci_arttext\&pid=S1415-52732005000400002\&lng=pt\&nrm=iso $>$. Acesso em: 19 jan. 2014. doi: 10.1590/S1415-52732005000400002.

ORGANIZAÇÃO MUNDIAL DA SAÚDE. Organização Pan-Americana da Saúde. Amamentação. 2003. Disponível em: <http://www.opas.org.br/sistema/fotos/ amamentar.pdf>. Acesso em: 13 jan. 2014. 
OSIS, Maria José Duarte et al. Aleitamento materno exclusivo entre trabalhadoras com creche no local de trabalho. Revista de Saúde Pública, São Paulo, v. 38, n. 2, p. 172-179, abr. 2004. SciELO Brasil. Disponível em: <http://www.scielo. br/scielo.php?script=sci_arttext\&pid=S0034-89102004000200004\&lng=pt\&nr m=iso>. Acesso em: 19 jan. 2014. doi: 10.1590/S0034-89102004000200004.

PIOVESAN, Flávia. Temas de direitos humanos. 3. ed. São Paulo: Saraiva, 2009.

REA, Marina Ferreira. Substitutos do leite materno: passado e presente. Revista de Saúde Pública, São Paulo, v. 24, n. 3, p. 241-249, jun. 1990. SciELO Brasil. Disponível em: <http://www.scielo.br/scielo.php?script=sci_ arttext\&pid=S0034-89101990000300011\&lng=pt\&nrm=iso >. Acesso em: 11 jan. 2014. doi: 10.1590/S0034-89101990000300011.

et al. Possibilidades e limitações da amamentação entre mulheres trabalhadoras formais. Revista de Saúde Pública, São Paulo, v. 31, n. 2, p. 149-156, abr. 1997. SciELO Brasil. Disponível em: <http://www.scielo.br/scielo. php?script=sci_arttext\&pid=S0034-89101997000200008\&lng=pt\&nrm=iso $>$. Acesso em: 19 jan. 2014. doi: 10.1590/S0034-89101997000200008.

; TOMA, Tereza Setsuko. Proteção do leite materno e ética. Revista de Saúde Pública, São Paulo, v. 34, n. 4, p. 388-395, ago. 2000. SciELO Brasil. Disponível em: <http://www.scielo.br/scielo.php?script=sci_ arttext\&pid=S0034-89102000000400012\&lng=pt\&nrm=iso >. Acesso em: 19 jan. 2014. doi: 10.1590/S0034-89102000000400012.

REALE, Miguel. Filosofia do direito. 19. ed. São Paulo: Saraiva, 1999.

RIBAS JR, R; MOURA, M.L.S; BORNSTEIN, M. H. Socioeconomic status in Brazilian psychological research: II. Socioeconomic status and parenting knowledge. Estudos de Psicologia, v. 8, 2003. Disponível em: http://redalyc. uaemex.mx/redalyc/src/inicio/ArtPdfRed.jsp?iCve=26180305. ISSN 1413-294X.

SANTOS, Boaventura de Sousa. Pela mão de Alice: o social e o político na pós-modernidade. 12. ed. São Paulo: Cortez, 2008.

SARLET, Ingo Wolfgang; FIGUEIREDO, Mariana Filchtiner. Algumas considerações sobre o direito fundamental à proteção e promoção do direito à saúde aos 20 anos da Constituição Federal de 1988 In: KEINERT, Tânia Margarete Mezzomo; PAULA, Silvia Helena Bastos de; BONFIM, José Ruben de Alcântara (Orgs.). As ações judiciais no SUS e a promoção do direito à saúde. São Paulo: Instituto de Saúde, 2009. p. 25-63.

SOLON, Ari Marcelo. Ética, cidadania e direito à saúde In: KEINERT, Tânia Margarete Mezzomo; PAULA, Silvia Helena Bastos de; BONFIM, José Ruben de Alcântara (Orgs.). As ações judiciais no SUS e a promoção do direito à saúde. São Paulo: Instituto de Saúde, 2009. p. 21-24.

SPITZ, Rene. O primeiro ano de vida. 6. ed. São Paulo: Martins Fontes, 1991. 
TEIXEIRA, Marizete Argolo; NITSCHKE, Rosane Gonçalves. Modelo de cuidar em enfermagem junto às mulheres-avós e sua família no cotidiano do processo de amamentação. Texto Contexto - enferm. Florianópolis, v. 17, n. 1, p. 183191, mar. 2008. SciELO Brasil. Disponível em: <http://www.scielo.br/scielo. php?script=sci_arttext\&pid=S0104-07072008000100021\&lng=pt\&nrm=iso $>$. Acesso em: 19 jan. 2014. doi: 10.1590/S0104-07072008000100021.

UNITED NATIONS DEVELOPMENT PROGRAMME. Capacity Development Empowering People and Institutions. Annual Report, PNUD, 2008.

VANNUCHI, Marli T Oliveira et al. Iniciativa Hospital Amigo da Criança e aleitamento materno em unidade de neonatologia. Revista de Saúde Pública, São Paulo, v. 38, n. 3, p. 422-428, jun. 2004. SciELO Brasil. Disponível em: <http://www. scielo.br/scielo.php?script=sci_arttext\&pid=S0034-89102004000300013\&lng=pt \&nrm=iso >. Acesso em: 19 jan. 2014. doi: 10.1590/S0034-89102004000300013.

VICTORIA, Ceres Gomes; KNAUTH, Daniela Riva; HASSEN, Maria de Nazareth Agra. Pesquisa qualitativa em saúde: uma introdução ao tema. Porto Alegre: Tomo Editorial, 2000.

WORLD HEALTH ORGANIZATION. The World Health Report 2008. Primary Health Care, now more than ever. Geneve: WHO, 2008. 